\title{
Role of Ascorbate in the Regulation of the Arabidopsis thaliana Root Growth by Phosphate Availability
}

\author{
Jarosław Tyburski, Kamila Dunajska-Ordak, Monika Skorupa, and Andrzej Tretyn \\ Chair of Plant Physiology and Biotechnology, Nicolaus Copernicus University, Gagarina 9, 87-100 Toruń, Poland \\ Correspondence should be addressed to Jarosław Tyburski, tybr@umk.pl
}

Received 24 July 2011; Accepted 4 October 2011

Academic Editor: Philip White

Copyright (๑) 2012 Jarosław Tyburski et al. This is an open access article distributed under the Creative Commons Attribution License, which permits unrestricted use, distribution, and reproduction in any medium, provided the original work is properly cited.

\begin{abstract}
Arabidopsis root system responds to phosphorus (P) deficiency by decreasing primary root elongation and developing abundant lateral roots. Feeding plants with ascorbic acid (ASC) stimulated primary root elongation in seedlings grown under limiting $\mathrm{P}$ concentration. However, at high P, ASC inhibited root growth. Seedlings of ascorbate-deficient mutant (vtc1) formed short roots irrespective of $\mathrm{P}$ availability. P-starved plants accumulated less ascorbate in primary root tips than those grown under high P. ASCtreatment stimulated cell divisions in root tips of seedlings grown at low P. At high P concentrations ASC decreased the number of mitotic cells in the root tips. The lateral root density in seedlings grown under P deficiency was decreased by ASC treatments. At high P, this parameter was not affected by ASC-supplementation. vtcl mutant exhibited increased lateral root formation on either, P-deficient or P-sufficient medium. Irrespective of P availability, high ASC concentrations reduced density and growth of root hairs. These results suggest that ascorbate may participate in the regulation of primary root elongation at different phosphate availability via its effect on mitotic activity in the root tips.
\end{abstract}

\section{Introduction}

It has been reported that phosphorus (P) availability affects root architecture in Arabidopsis. Seedlings of this plant, exposed to low $\mathrm{P}$ concentration $(1 \mu \mathrm{M})$, formed a highly branched root system with abundant lateral roots and a short primary root. Under these growth conditions primary, and secondary roots had an abundance of long root hairs. Under high $\mathrm{P}$ concentrations $(1 \mathrm{mM})$, the root system was composed of a long primary root with few lateral roots and short root hairs [1-3].

$\mathrm{P}$ deficiency responses of the root system are dependent on changes in cell proliferation. Under low $\mathrm{P}$ conditions, the reduction in primary root growth is due to inhibition of cell division and cell differentiation within the primary root meristem. The mitotic activity is relocated to the sites of lateral root formation, resulting in increased lateral root density. However, similar to the primary root tip, cell differentiation in older lateral roots occurs within the apical root meristem, which results in the arrest of lateral root elongation [4]. Besides the reduction in cell division rate, low $\mathrm{P}$ treatment inhibits cell elongation and reduces the number of cells in root elongation zone $[4,5]$.

Little is known about the mechanisms underlying the alteration in growth and development of Arabidopsis roots after plants are exposed to limiting $\mathrm{P}$ supply. It has been demonstrated that an arrest of root growth under low $\mathrm{P}$ concentration is dependent on the direct contact of growing root tips with the medium where $\mathrm{P}$ sensing occurs. This effect is mediated by two multicopper oxidases, LPR1 and LPR2, expressed in the root tip including the meristem and the root cap [6]. Recently, an important role in phosphate sensing and in root response to low $\mathrm{P}$ was attributed to PHOSPHATE DEFICIENCY RESPONSE 2 gene (PDR2) encoding a P5type ATPase that is required for proper expression of the SCARECROW gene (SCR). SCR is a key regulator in tissue patterning and stem-cell maintenance in apical root meristem [7]. Both, LPR1 and PDR2 are associated with the endoplasmic reticulum (ER). This finding points at the role of an ER-resident pathway in adjusting root meristem activity in response to external phosphate [8]. 
Published data suggests that the reduced elongation rate of primary roots of P-starved plants results from increased auxin accumulation in the root apical meristem [9]. However, other authors have proposed an auxin-independent process responsible for the primary root growth arrest under low $\mathrm{P}$ conditions. Increased lateral root formation under low $\mathrm{P}$ availability is related to auxin transport and signaling [3].

Besides the hormones, other endogenous factors mediate root developmental responses to nutrient deprivation. Shin and Schatchman [10] have demonstrated that $\mathrm{K}^{+}$deprivation is followed by an increase in $\mathrm{H}_{2} \mathrm{O}_{2}$ production in specific regions of the root. Accumulation of reactive oxygen species (ROS) in the roots of $\mathrm{K}^{+}$-starved plants was localized just behind the elongation zone (where $\mathrm{K}^{+}$active transport and translocation take place). It was also shown that $\mathrm{H}_{2} \mathrm{O}_{2}$ plays a role in controlling the expression of some genes in response to $\mathrm{K}^{+}$deprivation [10]. ROS accumulation in P-deprived roots has also been reported. Under low $\mathrm{P}$ conditions, increased ROS production was observed in the cortex. In contrast to P-starved roots, ROS accumulation in $\mathrm{K}^{+}$- and $\mathrm{NO}_{3}{ }^{-}$-deprived organs occurred in the epidermis rather than in the cortex [11].

Another component of cellular redox systems-ascorbate, is directly involved in the regulation of two processes that mediate morphogenic responses of root systems to nutrient availability: cell division and elongation. It has been shown that high ascorbic acid (ASC) concentrations are required for normal progression of the cell cycle in meristematic tissues [12-14]. ASC was identified as a factor necessary for G1-S transition. ASC addition to the cells of the root quiescent center induces these normally nondividing cells to pass from $G 1$ into the $S$ phase $[13,15]$. Besides its effect on cell proliferation, ASC stimulates cell elongation by increasing cell wall extensibility $[16,17]$.

In the present study, we address the role of ascorbate in the regulation of root system architecture under different $\mathrm{P}$ availability. Wild-type Arabidopsis seedlings grown on media containing low or high $\mathrm{P}$ concentrations supplemented with various ASC concentration as well as ascorbate-deficient $v t c 1$ mutants [18], were used in the study. Ascorbate concentration, and its effects on the primary root length, lateral root density, and length were analyzed. We also demonstrate the effect of ASC on the mitotic activity in the primary root meristem of seedlings grown under different phosphate regimes. Finally, the role of ASC in root hair development is assessed.

\section{Materials and Methods}

2.1. Plant Material. Arabidopsis wild-type plants (ecotype Col 0 ) and vitamin C-1 (vtc1) mutants were used. Seeds of wild-type and mutant plants were purchased from Nottingham Arabidopsis Stock Centre (University of Nottingham, UK). Seeds were soaked in sterile distilled water for $30 \mathrm{~min}$. Surface sterilization of the seeds was performed with $95 \%$ $(\mathrm{v} / \mathrm{v})$ ethanol for $5 \mathrm{~min}$ followed by $20 \%$ (v/v) bleach for 7 min. Subsequently, the seeds were washed several times in sterile water and sown onto culture media in Petri dishes. Seedlings were grown on the Murashige and Skoog
[19] medium modified according to López-Bucio et al. [2]. In order to provide phosphate deficiency or phosphate sufficiency (control) conditions two basal media were applied. Phosphate deficient media contained $1 \mu \mathrm{M}$ $\mathrm{NaH}_{2} \mathrm{PO}_{4}$, and $\mathrm{P}$ sufficient media contained $1 \mathrm{mM} \mathrm{Na}_{2} \mathrm{HPO}_{4}$ [2]. Seedlings were grown on unsupplemented media or on media supplemented with $100,200,300,400$, or $500 \mu \mathrm{M}$ ASCNa. ASCNa solution was filter-sterilized before adding to the autoclaved medium. Before the culture was initiated, the dishes were placed in dark at $4^{\circ} \mathrm{C}$ for 48 hours to promote and synchronize germination [2]. Seedlings were grown at $25^{\circ} \mathrm{C}$ under continuous white light with standard irradiation $\left(431 \mu \mathrm{mol} \mathrm{m} \mathrm{m}^{-2} \mathrm{~s}^{-1}\right)$ provided by Osram $30 \mathrm{~W} / 11$ 860 "Daylight” fluorescent tubes (Osram, Berlin, Germany).

2.2. The Analysis of the Root System Architecture. Control and ascorbate-treated seedlings were photographed and the images were analyzed using Image Gauge software (Fujifilm, Japan). Length of the primary roots, number and length of the lateral roots, and the number and length of root hairs were determined. Density of lateral roots, that is, number of lateral roots $/ \mathrm{cm}$ of primary root, and root hair density, that is, number of root hairs/mm of primary root, were calculated. Length of the primary roots, lateral root density, and lateral root length were determined after 12 days of culture on basal- or ASC-supplemented media. Root hair density and length were analyzed using 5-day-old seedlings.

2.3. Determination of Cell Division Frequency. Cell division frequency was determined microscopically in root tip squash preparations by inspecting at least 1000 cells and expressed as a percentage of mitotic cells in a single-root-tip squash. Roots were fixed in a 3:1 ethanol: acetic acid (v/v), hydrolyzed in $1 \mathrm{~N} \mathrm{HCl}$ for $1 \mathrm{~min}$, washed in a $50 \mathrm{mM}$ phosphate buffer (pH 7.5), and stained with 4,6-diamidino-2-phenylindole (DAPI; $0.1 \mathrm{mg} \mathrm{L}^{-1}$ ) for $10 \mathrm{~min}$. Segments, $1 \mathrm{~mm}$ in length, starting from the root tip were dissected, squashed in a drop of $50 \mathrm{mM}$ phosphate buffer ( $\mathrm{pH} 7.5)$, and observed under fluorescent microscope at an excitation wavelength of $365 \mathrm{~nm}$. Mitotic activity in the root tips was analyzed after 8 and 12 days of culture.

2.4. Ascorbate and Dehydroascorbate Determination. Concentrations of the reduced and oxidized form of ascorbate were determined in the apices of primary roots (samples consisted of approximately final $0.5 \mathrm{~cm}$ of the primary root) of Arabidopsis seedlings. The samples were homogenized in liquid nitrogen and extracted for $15 \mathrm{~min}$ with $6 \%$ trichloroacetic acid (TCA) at $0{ }^{\circ} \mathrm{C}$. Subsequently, $6 \%$ TCA was added to the samples up to $0.5 \mathrm{~cm}^{3}$. The homogenate was centrifuged at $15000 \times \mathrm{g}$ for $5 \mathrm{~min}$ at $4^{\circ} \mathrm{C}$. ASC and DHA were determined after the reduction of dehydroascorbate to ascorbate with dithiotreitol (DTT) and measured as described by Kampfenkel et al. [20]. The assay is based on the reduction of $\mathrm{Fe}^{3+}$ to $\mathrm{Fe}^{2+}$ by ASC and the spectrophotometric detection of $\mathrm{Fe}^{2+}$ complexed with $2.2^{\prime}-$ dipirydyl. DHA content $(\mu \mathrm{g} / \mathrm{g} \mathrm{fw})$ in extracts was calculated from the difference between ASC+DHA and ASC ( $\mu \mathrm{g} / \mathrm{g} \mathrm{fw})$. ASC and DHA content in root apices were determined after 
12 days of culture. Ascorbate redox state was expressed as $([$ ASC $] /[$ ASC + DHA $]) \times 100$.

\section{5. $\mathrm{H}_{2} \mathrm{O}_{2}$ Localization in the Root-Hair-Forming Zone of the} Primary Root. Patterns of $\mathrm{H}_{2} \mathrm{O}_{2}$ accumulation were studied with $2^{\prime}, 7^{\prime}$-dichlorodihydrofluorescein (DCFH) diacetate. DCFH-diacetate can cross the plasma membrane and, after being deacetylated by endogenous esterase, liberates DCFH in the cytoplasm, where it is oxidized in the reaction with $\mathrm{H}_{2} \mathrm{O}_{2}$ to highly fluorescent $2^{\prime}, 7^{\prime}$-dichlorofluorescein (DCF) [21]. In order for the dye to infiltrate the cells, roots were incubated for $15 \mathrm{~min}$ in $50 \mathrm{mM}$ phosphate buffer $(\mathrm{pH}$ 7.5) containing $50 \mu \mathrm{M}$ DCFH-diacetate and subsequently rinsed with phosphate buffer and imaged employing the Eclipse (Nicon) confocal microscope using $488 \mathrm{~nm}$ excitation and $525 \mathrm{~nm}$ emission spectra [22]. Optical sections were collected with a $z$ focus increment of $5 \mu \mathrm{m} . \mathrm{H}_{2} \mathrm{O}_{2}$ distribution patterns were analyzed in 5-day-long seedling of wild-type control plants, plants treated with $500 \mu \mathrm{M}$ ASC, and $v t c 1$ mutant plants. The experiment was repeated three times. The photographs show the representative view chosen from at least 15 plants analyzed in each experiment.

2.6. Statistics. Student's $t$-test was applied to determine the statistical significance of the results as compared to the control. The data for ASC/DHA determination represent the mean and standard deviation (SD) of at least three independent experiments. At least 30 seedlings were used in each replicate to obtain the ascorbate extracts. Data for root number and root length represents the mean and SD of three independent experiments with at least 25 seedlings in each replicate.

\section{Results}

3.1. The Effect of ASC on Root System Architecture in the Arabidopsis Seedlings Grown at Low $\left(1 \mu \mathrm{MPO}_{4}{ }^{3-}\right)$ and High (1 $\mathrm{mM} \mathrm{PO}_{4}{ }^{3-}$ ) Phosphate Concentration. Control seedlings grown under low $\mathrm{P}$ concentration produced shorter primary root when compared to those cultured on the medium supplemented with high P (Figures 1, 2(a), and 2(f)). In contrast to the primary root, lateral roots of plants grown at low $\mathrm{P}$ conditions were longer, when compared to those, formed by seedlings grown at high $\mathrm{P}$ availability (Table 1(a)). Supplementing ASC to the medium affected the growth of both, the primary root and the lateral roots of seedlings cultured under P-deficient or P-sufficient medium (Figure 2, Table 1(a)). When plants were grown under low P, ASC in concentrations of 300 and $400 \mu \mathrm{M}$ significantly stimulated primary root elongation. Highest stimulatory effect was observed when $300 \mu \mathrm{M}$ ASC was added to the medium. ASC concentrations higher than $400 \mu \mathrm{M}$ did not result in further stimulation of primary root growth. On the contrary, seedlings cultured in the presence of $500 \mu \mathrm{M}$ ASC formed slightly shorter roots than untreated controls, however, the difference was not statistically significant (Figure 1). Further increase in ASC concentration in the medium resulted in significant inhibition of primary root growth (data not shown). As opposed to plants grown under P deficiency, when plants

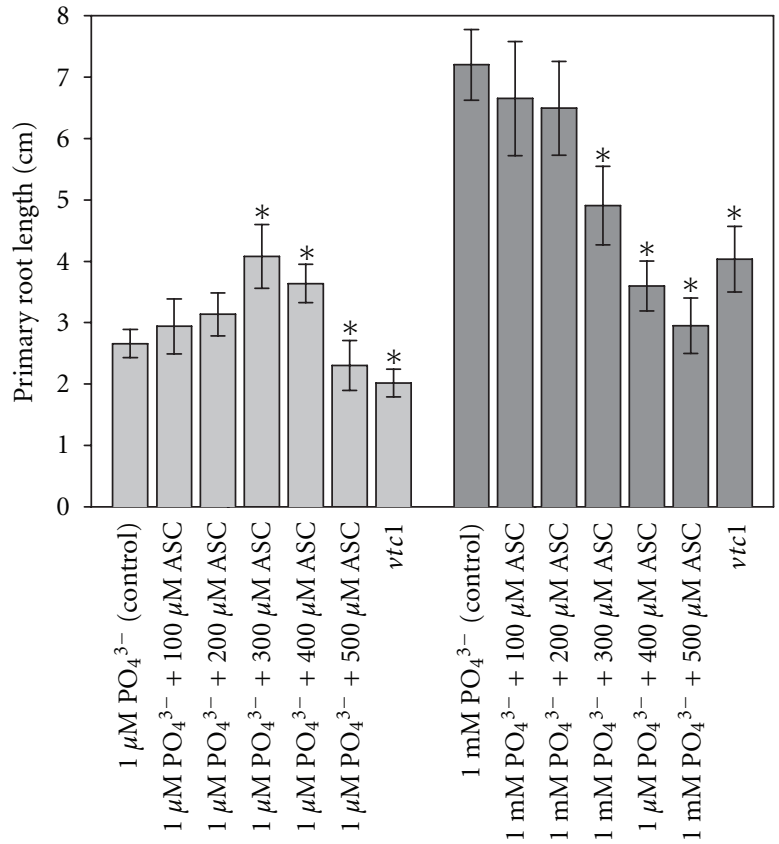

FIGURE 1: Effect of phosphate availability and ascorbate concentration on the length of the primary root of the Arabidopsis seedlings. Wild-type (Col 0) and $v t c 1$ mutant seedlings were grown 12 days on vertically oriented agar plates containing low $(1 \mu \mathrm{M}) \mathrm{P}$ or high ( $1 \mathrm{mM}) \mathrm{P}$ medium, after that, primary root length was determined. Wild-type seedlings were cultured on media supplemented with varying concentrations of ASC or on ascorbate-free media (control). Seedlings of $v t c 1$ mutant were cultured on ascorbatefree media. Values shown represent the mean of at least 50 seedlings \pm SD. An asterisk denotes significant differences from the control with $P<0.05$.

were cultured under high P, ASC concentrations applied did not stimulate primary root growth. The lowest ASC concentrations, that is, 100 and $200 \mu \mathrm{M}$ did not significantly affect primary root growth. Higher concentrations, in a dose-dependent manner, inhibited primary root elongation (Figure 1). Seedlings of $v t c 1$ mutants cultured on both, P-deficient or P-sufficient medium, formed significantly shorter primary roots than wild-type plants (Figures 1, 2(a), 2(d), 2(f), and 2(i)). When vtc1 mutants were fed with $300 \mu \mathrm{M}$ ASC, they formed roots of the length comparable with wild-type plants (Figures $2(\mathrm{e})$ and $2(\mathrm{j})$ ).

The length of lateral roots was negatively affected by exogenous ASC under both phosphate regimes (Table 1(a)). When plants were grown under low P availability, all ASC concentrations applied significantly decreased lateral root length (Table 1(a)). When plants were grown on medium containing $1 \mathrm{mM} \mathrm{P}, 100$ and $200 \mu \mathrm{M}$ ASC did not affect lateral root elongation, however, this process was strongly inhibited by higher ASC concentrations (Table 1(a)). Lateral roots of $v t c 1$ seedlings did not differ in length from the wild-type seedlings when plants were grown on either the Pdeficient or P-sufficient medium (Table 1(a)).

The density of lateral roots was calculated to normalize the effects of $\mathrm{P}$ availability and ASC application on primary 


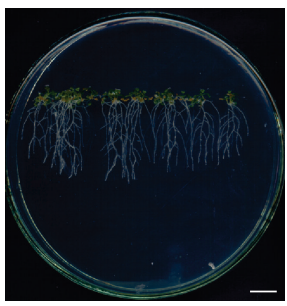

(a)

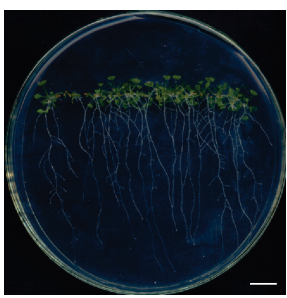

(f)

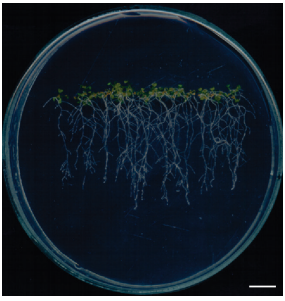

(b)

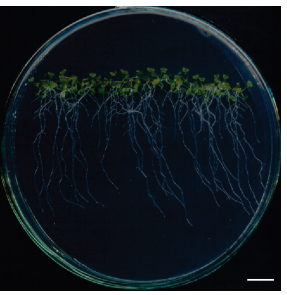

(g)

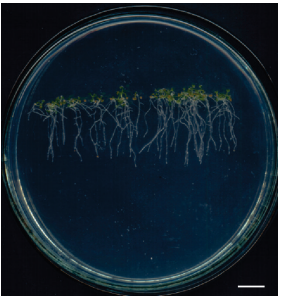

(c)

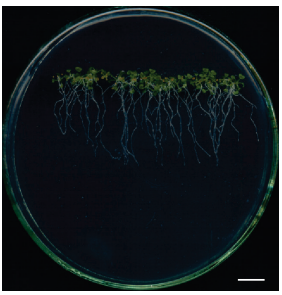

(h)

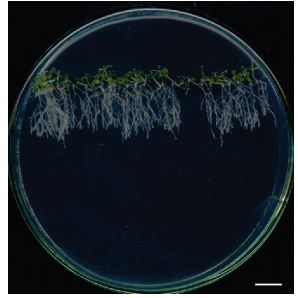

(d)

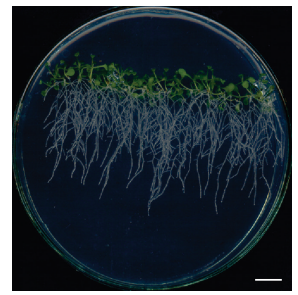

(i)

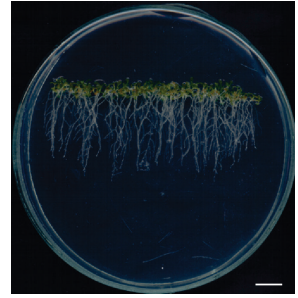

(e)

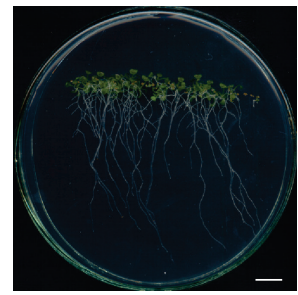

(j)

FIGURE 2: Effect of phosphate availability and ascorbate concentration on Arabidopsis root architecture. Wild-type (Col 0 ) seedlings were grown in the presence of the low $(1 \mu \mathrm{M}) \mathrm{P}$ concentration (a) or on the same medium supplemented with $300 \mu \mathrm{M}$ ASC (b) or $500 \mu \mathrm{M}$ ASC (c). $v t c 1$ seedlings were grown in the presence of the low $(1 \mu \mathrm{M}) \mathrm{P}$ concentration (d) or on the same medium supplemented with $300 \mu \mathrm{M}$ ASC (e). Wild-type Col 0 seedlings were grown in the presence of high ( $1 \mathrm{mM}) \mathrm{P}$ (f) or on the same medium supplemented with $300 \mu \mathrm{M}$ ASC (g) or $500 \mu \mathrm{M}$ ASC (h). vtcl seedlings were grown in the presence of high (1 mM) P (i) or on the same medium supplemented with $300 \mu \mathrm{M}$ ASC (j). Seedlings were photographed 12 days after germination. Bar $=1 \mathrm{~cm}$.

TABLE 1: Effect of ASC on the lateral root number, lateral root length, and lateral root density.

(a) Lateral root length $(\mathrm{mm})$

\begin{tabular}{lcccccc}
\hline $\begin{array}{l}1 \mu \mathrm{M} \mathrm{PO}_{4}{ }^{3-} \\
\text { Control }\end{array}$ & $100 \mu \mathrm{M}$ ASC & $200 \mu \mathrm{M}$ ASC & $300 \mu \mathrm{M}$ ASC & $400 \mu \mathrm{M}$ ASC & $500 \mu \mathrm{M} \mathrm{ASC}$ & $v t c 1$ \\
\hline $\begin{array}{l}8,36 \pm 0,29 \\
1 \mathrm{mM} \mathrm{PO}_{4}{ }^{3-}\end{array}$ & $6,30 \pm 0,49^{*}$ & $5,55 \pm 0,43^{*}$ & $5,12 \pm 0,37^{*}$ & $4,52 \pm 0,36^{*}$ & $3,51 \pm 0,30^{*}$ & $7,46 \pm 0,24$ \\
Control & $100 \mu \mathrm{M} \mathrm{ASC}$ & $200 \mu \mathrm{M}$ ASC & $300 \mu \mathrm{M}$ ASC & $400 \mu \mathrm{M} \mathrm{ASC}$ & $500 \mu \mathrm{M} \mathrm{ASC}$ & $v t c 1$ \\
\hline $5,29 \pm 0,52$ & $5,69 \pm 0,58$ & $4,94 \pm 0,61$ & $3,64 \pm 0,40^{*}$ & $3,62 \pm 0,36^{*}$ & $2,71 \pm 0,32^{*}$ & $5,55 \pm 0,15$ \\
\hline
\end{tabular}

(b) Lateral root density (number of lateral roots/cm of primary root)

\begin{tabular}{llllllr}
\hline $\begin{array}{l}1 \mu \mathrm{M} \mathrm{PO}_{4}{ }^{3-} \\
\text { Control }\end{array}$ & $100 \mu \mathrm{M}$ ASC & $200 \mu \mathrm{M}$ ASC & $300 \mu \mathrm{M}$ ASC & $400 \mu \mathrm{M}$ ASC & $500 \mu \mathrm{M}$ ASC & $v t c 1$ \\
\hline $3,22 \pm 0,47$ & $2,76 \pm 0,56$ & $2,55 \pm 0,45^{*}$ & $1,96 \pm 0,43^{*}$ & $1,68 \pm 0,40^{*}$ & $1,87 \pm 0,38^{*}$ & $5,30 \pm 1,05^{*}$ \\
$1 \mathrm{mM} \mathrm{PO}_{4}{ }^{3-}$ & & & & & \\
Control & $100 \mu \mathrm{M}$ ASC & $200 \mu \mathrm{M}$ ASC & $300 \mu \mathrm{M}$ ASC & $400 \mu \mathrm{M}$ ASC & $500 \mu \mathrm{M} \mathrm{ASC}$ & $v t c 1$ \\
\hline $1,17 \pm 0,28$ & $1,31 \pm 0,27$ & $1,03 \pm 0,17$ & $1,25 \pm 0,18$ & $1,20 \pm 0,19$ & $0,91 \pm 0,32$ & $3,39 \pm 0,27^{*}$
\end{tabular}

Lateral root number and lateral root density were determined after 12 days of culture. Arabidopsis seedlings were grown on media containing $1 \mu \mathrm{M} \mathrm{PO}_{4}{ }^{3-}$ or $1 \mathrm{mM} \mathrm{PO}_{4}{ }^{3-}$ or on the same media supplemented with 100-500 $\mu \mathrm{M}$ ASC. Seedlings of vtcl mutant were grown on medium containing either $1 \mu \mathrm{M} \mathrm{PO}_{4}{ }^{3-}$ or $1 \mathrm{mM} \mathrm{PO}_{4}{ }^{3-}$. Data represent mean and standard deviation. * Significant differences from control with $P<0.05$.

root length. This parameter decreased approximately 2 -fold in plants grown under high $\mathrm{P}$ conditions, when compared to plants grown under low $\mathrm{P}$ conditions (Table 1(b)). Treatment with ascorbate concentration of $200 \mu \mathrm{M}$ or higher resulted in a significant decrease of lateral root density in plants cultured under low P. When plants were grown at $1 \mathrm{mM} \mathrm{P}$, ASC concentration did not change the lateral root density. Irrespective of the $\mathrm{P}$ concentration in medium, seedlings of $v t c 1$ mutant were characterized by a significantly increased lateral root density when compared to wild-type plants (Table 1(b)).

3.2. ASC Concentration and Redox State in Arabidopsis Seedlings Grown at Low $\left(1 \mu \mathrm{M} \mathrm{PO} \mathrm{PO}_{4}{ }^{3-}\right)$ and High (1 $\mathrm{mM} \mathrm{PO}_{4}{ }^{3-}$ ) Phosphate Concentration. The concentration of endogenous ascorbate (ASC) and dehydroascorbate 


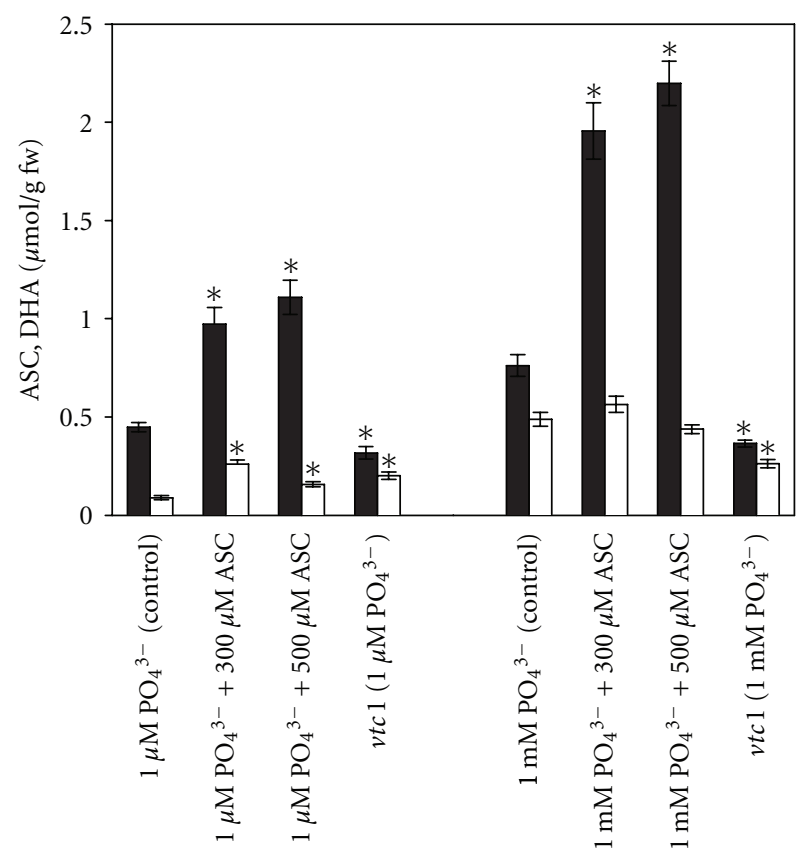

FIgURe 3: Ascorbate (black bars) and dehydroascorbate (white bars) content in root apices of the seedlings of wild-type Arabidopsis thaliana (Col 0 ) and $v t c 1$ mutant grown 12 days on vertically oriented agar plates on the low $(1 \mu \mathrm{M}) \mathrm{P}$ or high (1 mM) P medium. Another set of wild-type seedlings was grown on low $\mathrm{P}$ or high $\mathrm{P}$ media supplemented with 300 or $500 \mu \mathrm{M}$ ASC. Mean and \pm SD is shown. An asterisk denotes significant differences from the control with $P<0.05$.

(DHA) was determined in the primary root apices (Figure 3). Additionally, ASC concentration in the media was measured during the culture, in order to detect possible ASC breakdown in the media. However, no significant decrease in ASC concentration in the media was detected (data not shown).

Root tips of seedlings grown under high $\mathrm{P}$ concentration accumulated more ASC and DHA than those grown under $\mathrm{P}$ deficiency. And under high $\mathrm{P}$ concentration, the participation of DHA in total ascorbate pool was higher when compared to low P conditions (Figure 3, Table 2). Root tips of $v t c 1$ mutants cultured on phosphate-sufficient medium contained significantly less amounts of both, ASC and DHA than the wild-type plants. However, when mutant plants where grown on P-deficient medium, only ASC content was reduced in comparison to the wild-type plants, whereas DHA concentration was slightly, but significantly, increased (Figure 3). Total ascorbate pool in the root tips of $v t c 1$ was more oxidized when compared to wild-type plants if seedlings were grown under $\mathrm{P}$ deficiency. In contrast, ascorbate redox state did not differ significantly between $v t c 1$ and wild-type, if plants were grown on phosphate-sufficient medium (Table 2).

Adding ASC to either P-deficient or P-sufficient medium resulted in a strong increase in ascorbate content in the root tips. It should be noted that seedlings, grown under low $\mathrm{P}$ conditions, reacted to ASC treatments with a smaller increase in ascorbate concentration in the root apices when compared
TABLE 2: Effect of phosphate availability and exogenous ASC on ascorbate redox state $(([\mathrm{ASC}] /[\mathrm{ASC}+\mathrm{DHA}]) \times 100)$ in root apices of Arabidopsis seedlings.

\begin{tabular}{llll}
\hline $\begin{array}{l}1 \mu \mathrm{M} \mathrm{PO}_{4}{ }^{3-} \\
\text { control }\end{array}$ & $300 \mu \mathrm{M}$ ASC & $500 \mu \mathrm{M}$ ASC & $v t c 1$ \\
\hline $83,3 \pm 5,0$ & $78,9 \pm 7,9$ & $87,5 \pm 7,8$ & $61,1 \pm 8,9^{*}$ \\
$1 \mathrm{mM} \mathrm{PO}_{4}{ }^{3-}$ & & & \\
control & $300 \mu \mathrm{M} \mathrm{ASC}$ & $500 \mu \mathrm{M}$ ASC & $v t c 1$ \\
\hline $60,9 \pm 7,2$ & $77,6 \pm 7,2^{*}$ & $83,3 \pm 5,1^{*}$ & $58,2 \pm 4,7$ \\
\hline
\end{tabular}

Ascorbate redox state $(([\mathrm{ASC}] /[\mathrm{ASC}+\mathrm{DHA}]) \times 100)$ in root tips of Arabidopsis seedlings was determined after 12 days of culture. Arabidopsis seedlings were grown on media containing $1 \mu \mathrm{M} \mathrm{PO}_{4}{ }^{3-}$ or $1 \mathrm{mM} \mathrm{PO}_{4}{ }^{3-}$ or on the same media supplemented with 100 or $500 \mu \mathrm{M}$ ASC. Seedlings of $v t c 1$ mutant were grown on medium containing either $1 \mu \mathrm{M} \mathrm{PO}_{4}{ }^{3-}$ or $1 \mathrm{mM}$ $\mathrm{PO}_{4}{ }^{3-}$. ${ }^{*}$ Significant differences from control with $P<0.05$.

to the roots of plants grown under high $\mathrm{P}$ conditions (Figure 3). Under low P amounts, an increase in ASC content was accompanied by an elevation in DHA concentration. However, due to a strong rise in ASC concentration, an ascorbate redox state remained unchanged when compared to untreated control (Table 2). Contrary to P-deficient plants, DHA concentration was unchanged, by ASC treatment, in root tips of plants cultured on high $\mathrm{P}$ medium (Figure 3 ). Consequently, an increase in ASC content in root apices of ASC-treated plants shifted ascorbate/dehydroascorbate ratio towards more reduced redox state (Table 2).

3.3. Effects of ASC on Cell Divisions in the Primary Root Tips of the Arabidopsis Seedlings Grown at Low $\left(1 \mu \mathrm{MPO}_{4}{ }^{3-}\right)$ and High ( $1 \mathrm{mM} \mathrm{PO}_{4}{ }^{3-}$ ) Phosphate Concentration. To study whether the effects of ASC concentration on root elongation in seedlings grown under low $\mathrm{P}$ or high $\mathrm{P}$ concentration are mediated by changes in the cell division rate in the root meristem, we determined the frequency of dividing cells in the primary root tips of wild-type control plants, ASC-treated plants and $v t c 1$ mutant plants. Cell division activity was assayed twice during the culture period: 8 and 12 days after germination. Mitosis frequency in root tips of wild-type plants grown under low $\mathrm{P}$ was approximately six times lower than the corresponding part of the plants' root cultured at high P (Figure 4). At low P conditions, increasing ASC concentrations in the medium resulted in a gradual stimulation of mitotic activity. Highest increase in the rate of cell divisions was observed in seedlings cultured in the presence of $300 \mu \mathrm{M}$ ASC. With higher ASC concentrations, its stimulatory effect was decreased proportionally to the ASC concentration (Figure 4). In contrast to seedlings grown at $1 \mu \mathrm{M} \mathrm{P}$, treatments with a series of ASC concentrations led to a gradual decrease in the mitotic activity in root tips of high P-grown plants. Mitotic activity in the root tips of $v t c 1$ was strongly reduced when compared to wild-type controls irrespective of $\mathrm{P}$ concentration in the medium (Figure 4).

3.4. Effects of ASC on Root Hair Density and Elongation. Root hair development was studied in the area encompassing the final $5 \mathrm{~mm}$ of the primary root where root hairs are formed 


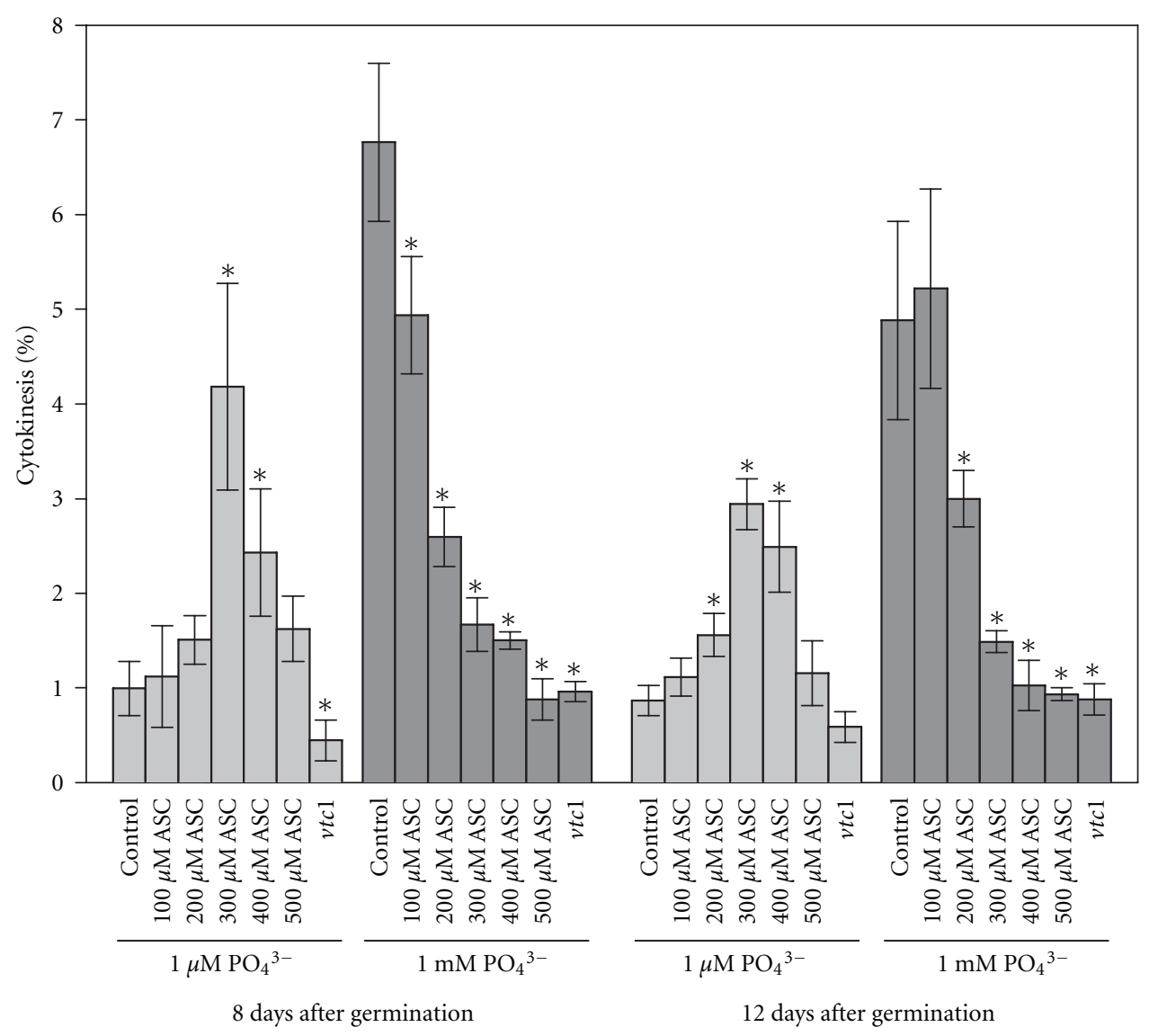

FIgURE 4: Effect of phosphate availability and ascorbate concentration on the cytokinesis frequency in the root tips of Arabidopsis thaliana. Mitotic activity in the root tips of wild-type ( $\mathrm{Col} 0)$ and $v t c 1$ seedlings was analyzed after 8 and 12 days of culture on the media containing low $(1 \mu \mathrm{M}) \mathrm{P}$ or high $(1 \mathrm{mM}) \mathrm{P}$ concentration. Wild-type seedlings were cultured on media supplemented with varying concentrations of ASC or on ascorbate-free media (control). Seedlings of $v t c 1$ mutant were cultured on ascorbate-free media. Each determination is based on at least three squash preparations. Mean value and \pm SD are indicated. Data represent mean and standard deviation. Asterisk indicates significant differences from the control at $P<0.05$.

and elongate. It was found that both the wild-type seedlings and $v t c 1$ mutants were characterized with a similar value of root hair density. This parameter was also not significantly affected by P availability (Figure 5(a)).

Root hair formation was affected by ASC supplementation to the medium. In the presence of high $\mathrm{P}$ concentration, ASC decreased the number of root hairs in a dose-dependent manner. When plants grown under $\mathrm{P}$ deficiency were analyzed, both, stimulatory and inhibitory effects of the ASC concentration applied were observed. The lowest ASC concentration $(100 \mu \mathrm{M})$ was found to, slightly but significantly, stimulate the density of root hairs. Higher concentrations did not significantly affect root hair formation. However, a significant the inhibitory effect was observed when the highest concentration $(500 \mu \mathrm{M})$ was applied (Figure 5(a)).

Root hair growth was strongly affected by $\mathrm{P}$ availability. Seedlings grown under limited P availability formed long root hairs in the apical part of the root, while those formed by plants grown on P-sufficient medium were approximately 4 times shorter (Figures 5(b), 6(a), and 6(f)). Root hairs of $v t c 1$ mutant seedlings were comparable in length with wild-type, when cultured under low $\mathrm{P}$ amount. In contrast to wild-type plants, root hairs of $v t c 1$ mutants were significantly longer than those of the wild-type when plants were grown under high $\mathrm{P}$ concentration (Figures 5(b), 6(f), and 6(j)). Wild-type plants grown in the presence of $100 \mu \mathrm{M}$ ASC formed longer root hairs when compared to untreated control under both, low and high $\mathrm{P}$, however, only under high $\mathrm{P}$ concentration the difference was significant (Figure 5(b)). ASC concentrations of 200 and $300 \mu \mathrm{M}$ did not affect the root hair length, however, it was strongly reduced when 400 or $500 \mu \mathrm{M}$ ASC was added to the medium (Figures 5(b) and 6).

Root hair development and elongation is regulated by reactive oxygen species (ROS) production in a root-hairforming zone [23]. Therefore, we asked whether changing ASC concentration in roots affected $\mathrm{H}_{2} \mathrm{O}_{2}$ concentration in the rooting zone. In order to assess the $\mathrm{H}_{2} \mathrm{O}_{2}$ concentrations in the root-hair-forming zone, the roots were stained with DCFH which is oxidized by $\mathrm{H}_{2} \mathrm{O}_{2}$ to the highly fluorescent $2^{\prime}, 7^{\prime}$-dichlorofluorescein (DCF). Within the root-forming zone, trichoblast cells, were characterized by the highest DCF fluorescence (Figure 7). Irrespective of P concentration 


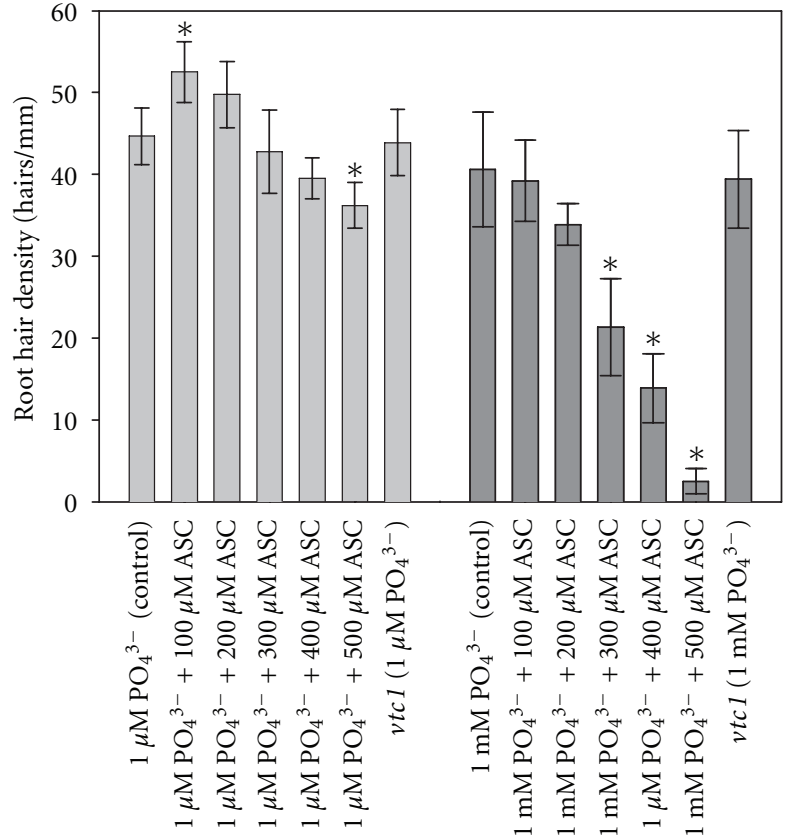

(a)

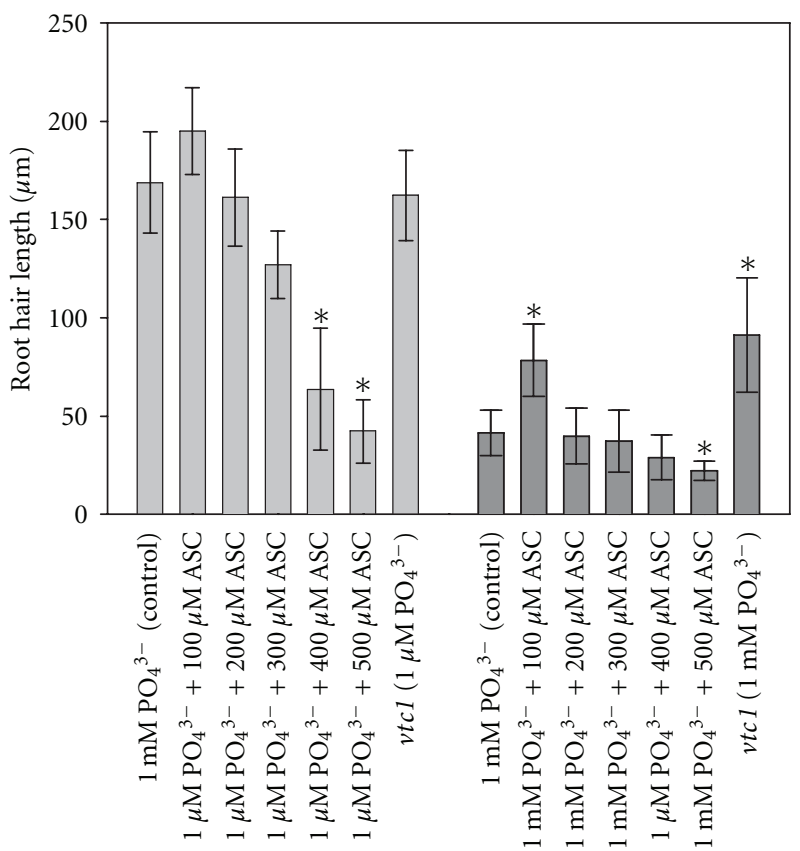

(b)

FIGURE 5: Effect of phosphate availability and ascorbate concentration on the root hair length and density of Arabidopsis wild-type (Col 0) and $v t c 1$ mutant seedlings. Wild-type seedlings were cultured on media supplemented with varying concentrations of ASC or on ascorbatefree media (control). Seedlings of $v t c 1$ mutant were cultured on ascorbate-free media. The length is the mean ( \pm SD) of 50 root hairs, root hair density (mean \pm SD) was determined on 25 roots. Asterisk indicates significant differences from the control at $P<0.05$.

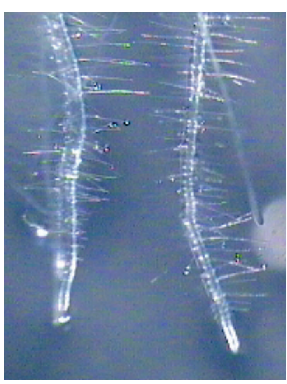

(a)

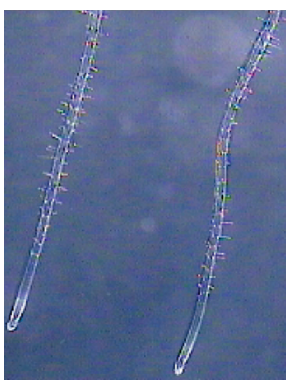

(f)

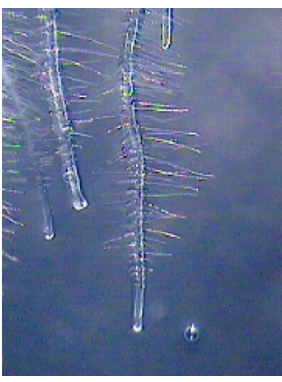

(b)

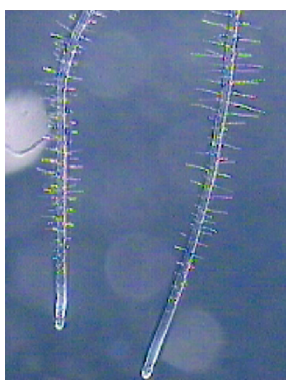

(g)

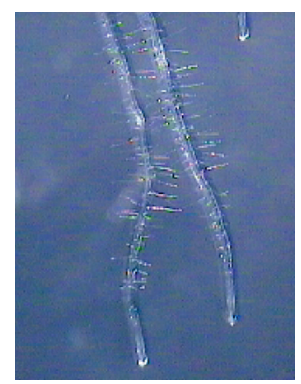

(c)

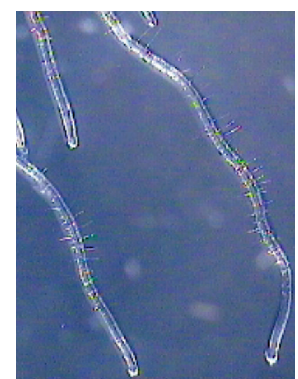

(h)

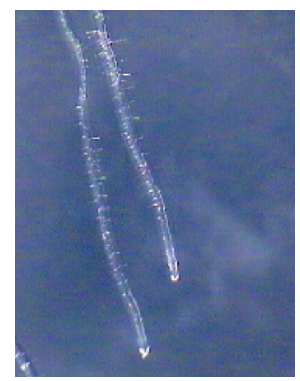

(d)

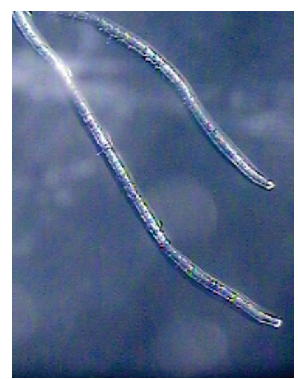

(i)

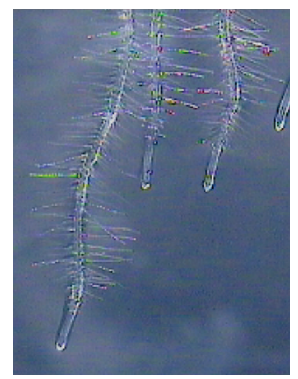

(e)

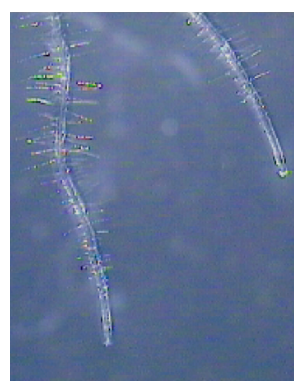

(j)

FIGURE 6: Effect of phosphate availability and ascorbate concentration on the development of root hairs in the apical part of primary roots of Arabidopsis wild-type ( $\mathrm{Col} 0)$ and $v t c 1$ seedlings. The pictures show a representative view of a root tips and root hair zone from seedlings grown for 5 days on the media containing low $(1 \mu \mathrm{M}) \mathrm{P}$ or high $(1 \mathrm{mM}) \mathrm{P}$ concentration. Wild-type (Col 0$)$ seedlings were grown in the presence of the low $(1 \mu \mathrm{M}) \mathrm{P}$ concentration (a) or on the same medium supplemented with $100 \mu \mathrm{M}$ ASC (b), $300 \mu \mathrm{M}$ ASC (c) or $500 \mu \mathrm{M}$ ASC (d). Another sets of wild-type seedlings were cultured on high ( $1 \mathrm{mM}) \mathrm{P}$ medium (f) or on the same medium supplemented with $100 \mu \mathrm{M}$ ASC (g), $300 \mu \mathrm{M}$ ASC (h) or $500 \mu \mathrm{M}$ ASC (i). Seedlings of $v t c 1$ mutants were grown on ascorbate-free media supplemented with low $(1 \mu \mathrm{M}) \mathrm{P}(\mathrm{e})$ or high $(1 \mathrm{mM}) \mathrm{P}(\mathrm{j})$ concentration. 


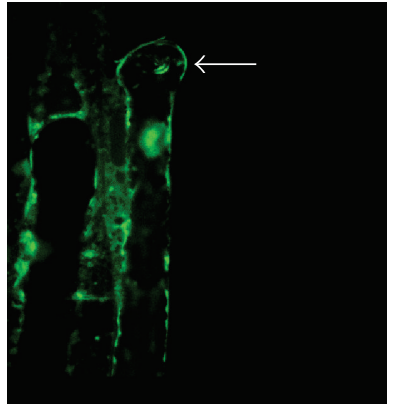

(a)

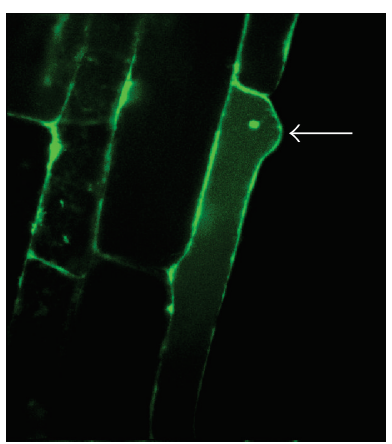

(d)

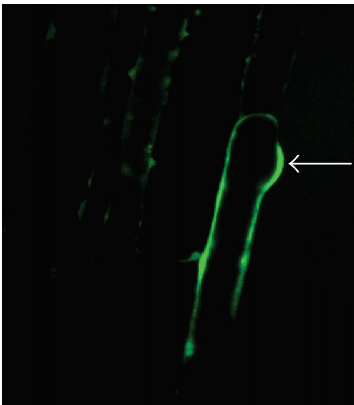

(b)

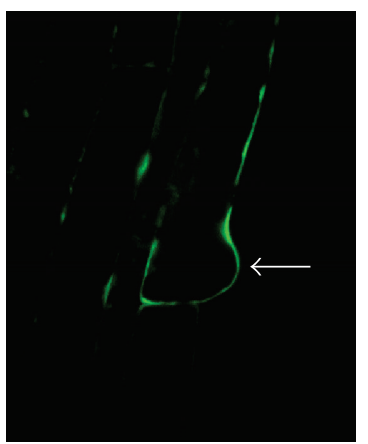

(e)

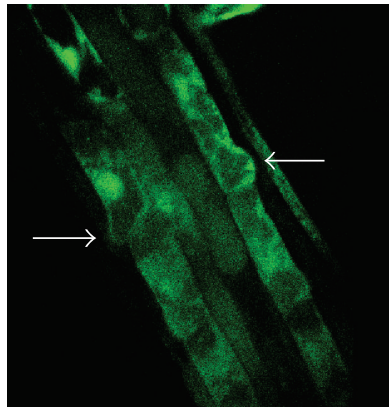

(c)

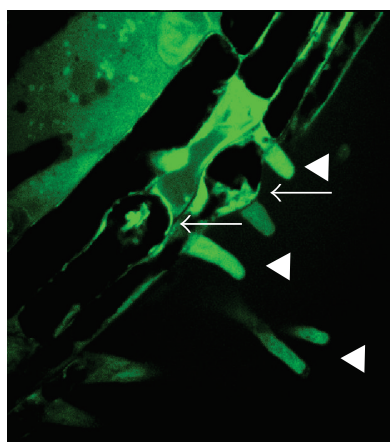

(f)

FIGURE 7: The sites of $\mathrm{H}_{2} \mathrm{O}_{2}$ production in the root-hair-forming zone of the roots of Arabidopsis wild type $(\mathrm{Col} 0)$ and $v t c 1$ seedlings. $\mathrm{H}_{2} \mathrm{O}_{2}$ was visualized by DCF fluorescence. $\mathrm{H}_{2} \mathrm{O}_{2}$ localization was determined in the differentiation zones of roots of wild-type seedlings grown on the medium containing $1 \mu \mathrm{M} \mathrm{P}$ (a), on the $1 \mu \mathrm{M}$ P medium supplemented with $500 \mu \mathrm{M}$ ASC (b), on the medium containing 1 mM P (d), or on the $1 \mathrm{mM}$ P medium supplemented with $500 \mu \mathrm{M}$ ASC (e). Seedlings of $v t c 1$ mutants were grown on ascorbate-free media supplemented with low $(1 \mu \mathrm{M}) \mathrm{P}(\mathrm{c})$ or high $(1 \mathrm{mM}) \mathrm{P}(\mathrm{f})$ concentration.

in the culture medium, we observed less DCF fluorescence (indicating reduced $\mathrm{H}_{2} \mathrm{O}_{2}$ concentration) in the root-hairforming zone when plants were treated with $500 \mu \mathrm{M}$ ASC (Figures $7(\mathrm{~b})$ and $7(\mathrm{e}))$, compared to untreated control (Figures $7(\mathrm{a})$ and $7(\mathrm{~d})$ ). $v t c 1$ mutants were characterized by more fluorescent cells in the root-hair-forming zone of when compared to wild-type plants (Figures 7(c) and 7(f)).

\section{Discussion}

It has been established that under P deficiency, the elongation of the Arabidopsis primary root is inhibited $[2,4,5,9]$. We demonstrate that the differences in the length of primary root observed at low and high $\mathrm{P}$ are accompanied by changes in ascorbate content and redox status. Root tips of P-starved plants are characterized by significantly lower ASC content than the organs of those grown under high $\mathrm{P}$ conditions. Under low P conditions, almost the entire ASC pool is reduced, while under high $\mathrm{P}$ concentration, an oxidized form of ascorbate constitutes about $40 \%$ of total pool of this antioxidant in the apical part of roots (Figure 3, Table 2).

Under low P, increase in the ASC content stimulated the growth of primary root. It was also observed that the seedlings of $v t c 1$ mutant, defective in ASC synthesis, produced shorter primary roots than wild-type seedlings (Figures 1 and 2(b)). These data suggest that the increase in endogenous ascorbate may partly reverse the inhibitory effect of low $\mathrm{P}$ availability on primary root elongation. Therefore, the lowering of ASC concentrations in roots of seedlings grown under $\mathrm{P}$ deficiency may participate in the mechanism of primary root growth inhibition. However, it should be noted that stimulatory effect of ASC was limited to a relatively narrow range of concentrations and growth inhibition was observed when plants were treated with higher concentrations of ASC.

In plants grown under high $\mathrm{P}$ concentrations, the length of the primary root was decreased upon addition of ASC to the medium. However, under high P availability, primary root elongation was also decreased in $v t c 1$ mutants (Figure 1). This observation is consistent with data reported by Olmos et al. [24] who also found the reduction in primary root length in $v t c 1$ plants when compared to wild-type plants. These results suggest that an optimal ASC concentration in roots is required to maintain a high rate of primary root elongation in plants grown under high $\mathrm{P}$ amounts. However, primary root length of $v t c 1$ is significantly longer on high $\mathrm{P}$ medium compared to low $\mathrm{P}$ medium (Figures 1, 2(d), and 2(i)), whereas roots of $v t c 1$ mutant accumulate similar ascorbate concentrations if grown under both phosphate conditions (Figure 3). These findings suggest, that besides ASC, other factors are responsible for high root-elongation rate under high $\mathrm{P}$ availability. 
Lateral root formation was inhibited by ASC, if low $\mathrm{P}$ concentration was present in the medium, whereas this parameter was not significantly affected by ASC-treatment under high $\mathrm{P}$ concentration. Moreover, irrespective of $\mathrm{P}$ availability, lateral root formation was increased in vtc1 mutant (Table 1(b)). This suggests that decreased ASC concentration promotes lateral root proliferation. Contrary to our results, Olmos et al. [24] did not report a difference in the lateral root number between $v t c 1$ and wild-type plants. However, they reported an increase in lateral root formation by $v t c 2$-another ASC-deficient mutant [24]. An increased number of lateral roots in $v t c$ mutants is consistent with the stimulatory role of ROS in lateral root formation and growth. ROS, required for lateral root formation, are produced by activation of the AtrbohC NADPH oxidase [23] and specifically localize in the lateral root primordia [25]. In its role as an antioxidant, ASC removes ROS which follows that low ASC availability in roots will favor lateral root formation [24].

Changes in the cell proliferation play an essential role in the onset of plant responses to $\mathrm{P}$ deficiency. A significant part of inorganic phosphate is used for DNA synthesis in dividing cells [4]. Under low P conditions, meristematic activity in the main root is blocked or slowed down and relocated to the sites of lateral root formation. Reduction in growth of primary root and lateral roots is due to a determinate, low $\mathrm{P}$-induced, root developmental programme that inhibits cell division in the primary root meristem and promotes differentiation within the root tip $[4,26]$. Consistently with aforementioned results, in our experiment, cytokinesis frequency in root tips of plants grown under $\mathrm{P}$ deficiency was significantly lower, compared to plants cultured at high $\mathrm{P}$ concentration (Figure 4).

Since ASC was demonstrated to stimulate G1-S transition, cell division is one of the possible ASC targets in the regulation of primary root growth $[13,14,27,28]$. Therefore, we checked the effect of ASC concentration on the frequency of cell divisions in root tips of plants grown under low or high $\mathrm{P}$ amounts. Mitotic activity in the root tips of $v t c 1$ mutants grown under P-deficient medium was lower than the wild-type plants treated with the same P concentration. The number of dividing cells increased in plants treated with ASC when grown under low P. The strongest stimulation occurred when $300 \mu \mathrm{M}$ ASC was applied. Higher and lower concentrations were less efficient in promoting cell divisions (Figure 4). ASC in $300 \mu \mathrm{M}$ concentration was also the most efficient in alleviating the inhibitory effect of low $\mathrm{P}$ on root elongation (Figure 1). This suggests that stimulatory effect of exogenous ASC on root elongation in plants grown under low $\mathrm{P}$ may result from the stimulatory effect of this antioxidant on cell divisions in the root meristem. In contrast to plants grown under low $\mathrm{P}$, under high $\mathrm{P}$ the mitotic activity in primary root apices was significantly inhibited by an increased ASC contents. Low frequency of cell divisions was also detected in root tips of ASC-deficient $v t c 1$ mutants grown at high $\mathrm{P}$ (Figure 4). Contrasting effects of ASC treatment on mitotic activity in low $\mathrm{P}$ and high P-grown plants suggest that maintaining the high rate of cell divisions in apical root meristem requires an optimal concentration of this antioxidant. This idea is also supported by the finding that at low $\mathrm{P}$, where initial ASC concentrations are low, the stimulatory effect of ASC on cell divisions is the highest at $300 \mu \mathrm{M}$ ASC but the stimulatory effect decreases in the presence of higher concentrations. In roots of plants grown under high $\mathrm{P}$, where endogenous ASC concentration in roots is high, ascorbate supplementation may result in supraoptimal ASC concentration which seems to inhibit cell divisions.

Recently, it has been proposed that inhibition of apical root meristem activity in low $\mathrm{P}$ is a consequence of increased Fe uptake and its subsequent toxicity [29-31]. Fe under biological conditions can generate toxic hydroxyl radicals via the Fenton reaction [32]. As an antioxidant, ASC may directly scavenge harmful radicals produced under iron overload, thus protecting meristematic cells in P-starved roots from oxidative stress. Alternatively, ASC may be involved in Fe homeostasis in the root apex, as it has been shown that ASC regulates Fe sequestration by iron-storage protein-ferritin [27]. Both mechanisms may possibly be involved in the stimulatory effect of exogenous ASC on cell division activity in root tips in plants grown under low $\mathrm{P}$ [33], however further experiments are required to test the afore-mentioned idea.

Root hair development is an important adaptation strategy under nutrient deficiency. In order to optimize $\mathrm{P}$ uptake, Arabidopsis plants growing on P-limiting media form longer root hairs when compared to those cultured under Psufficient conditions [34]. Because a characteristic feature of roots of P-deficient plants is the formation of long root hairs close to the root tip, in this work we measured the length of root hairs in the distal part of the root. ASC supplementation to the medium inhibited root hair elongation under both low and high $\mathrm{P}$ amounts, if the highest; 400 or $500 \mu \mathrm{M}$ ASC was applied. However, the reduction of ASC concentration in $v t c 1$ resulted in the stimulation of root hair growth when plants were grown under high $\mathrm{P}$ concentration (Figures 5(b) and $6(\mathrm{e}))$. Because root hair formation and elongation are dependent on ROS production in the trichoblasts [23], an inhibition of root hair length by ASC may result from ROS scavenging by ASC. To test this idea, we visualized ROS production in the root-hair-forming zones of plants grown on ASC-unsupplemented media or media supplemented with $500 \mu \mathrm{M}$ ASC; a concentration which significantly decreased both root hair density (Figure 5(a)) and length (Figures 5(b), $6(\mathrm{~d})$ and 6(i)). Lower levels of DCF fluorescence, indicating reduced ROS concentrations, were recorded in root-hairforming zones of ASC-treated plants (Figures 7(b) and 7(e)) when compared to relevant parts of the roots of wild-type plants (Figure $7(\mathrm{a})$ and $7(\mathrm{~d})$ ) or $v t c 1$ mutants (Figure 7(c) and $7(\mathrm{f})$ ) grown on ASC-free media, which suggests that ROS-scavenging in the root-hair-forming zone may possibly be responsible for reduced root hair length and density in seedlings grown in the presence of $500 \mu \mathrm{M}$ ASC.

It is intriguing that $100 \mu \mathrm{M}$ ASC, in contrast to higher ASC concentrations, stimulated root hair growth in plants grown under high $\mathrm{P}$ concentration (Figure 5(b)). These findings require further studies to be fully explained, however, they raise an idea that endogenous ASC may be engaged in 
the regulation of root hair elongation by controlling ROS levels in the root-hair-forming zone.

In conclusion, our data suggest that ascorbate may be engaged in the regulation of primary root elongation by $\mathrm{P}$ availability. The results reported here demonstrate that there are clear differences in ASC content and redox state in the apical parts of primary roots of plants grown under different regimes of phosphate availability. The idea of the involvement of ASC in P-dependent root growth response is supported by the finding that raising the endogenous ASC content by feeding plants with ASC partly reverses primary root growth inhibition in seedlings subjected to low $\mathrm{P}$ treatment. The effects of ASC on root growth are possibly mediated by its effect on cell division activity in the apical root meristem.

\section{Acknowledgment}

This work was financially supported by a Grant of the Rector of Nicolaus Copernicus University (Grant no. 525-B).

\section{References}

[1] L. C. Williamson, S. P. C. P. Ribrioux, A. H. Fitter, and H. M. O. Leyser, "Phosphate availability regulates root system architecture in Arabidopsis," Plant Physiology, vol. 126, no. 2, pp. 875-882, 2001.

[2] J. López-Bucio, E. Hernández-Abreu, L. Sánchez-Calderón, M. F. Nieto-Jacobo, J. Simpson, and L. Herrera-Estrella, "Phosphate availability alters architecture and causes changes in hormone sensitivity in the Arabidopsis root system," Plant Physiology, vol. 129, no. 1, pp. 244-256, 2002.

[3] J. López-Bucio, E. Hernández-Abreu, L. Sánchez-Calderón et al., "An auxin transport independent pathway is involved in phosphate stress-induced root architectural alterations in Arabidopsis. Identification of BIG as a mediator of auxin in pericycle cell activation," Plant Physiology, vol. 137, no. 2, pp. 681-691, 2005.

[4] L. Sánchez-Calderón, J. López-Bucio, A. Chacón-López, A. Gutiérrez-Ortega, E. Hernández-Abreu, and L. Herrera-Estrella, "Characterization of low phosphorus insensitive mutants reveals a crosstalk between low phosphorus-induced determinate root development and the activation of genes involved in the adaptation of Arabidopsis to phosphorus deficiency," Plant Physiology, vol. 140, no. 3, pp. 879-889, 2006.

[5] L. Sánchez-Calderón, J. López-Bucio, A. Chacón-López et al., "Phosphate starvation induces a determinate developmental program in the roots of Arabidopsis thaliana," Plant and Cell Physiology, vol. 46, no. 1, pp. 174-184, 2005.

[6] S. Svistoonoff, A. Creff, M. Reymond et al., "Root tip contact with low-phosphate media reprograms plant root architecture," Nature Genetics, vol. 39, no. 6, pp. 792-796, 2007.

[7] C. A. Ticconi, R. D. Lucero, S. Sakhonwasee et al., "ER-resident proteins PDR2 and LPR1 mediate the developmental response of root meristems to phosphate availability," Proceedings of the National Academy of Sciences of the United States of America, vol. 106, no. 33, pp. 14174-14179, 2009.

[8] H. Rouached, A. B. Arpat, and Y. Poirier, "Regulation of phosphate starvation responses in plants: signaling players and cross-talks," Molecular Plant, vol. 3, no. 2, pp. 288-299, 2010.
[9] P. Nacry, G. Canivenc, B. Muller et al., "A role for auxin redistribution in the responses of the root system architecture to phosphate starvation in Arabidopsis," Plant Physiology, vol. 138, no. 4, pp. 2061-2074, 2005.

[10] R. Shin and D. P. Schachtman, "Hydrogen peroxide mediates plant root cell response to nutrient deprivation," Proceedings of the National Academy of Sciences of the United States of America, vol. 101, no. 23, pp. 8827-8832, 2004.

[11] R. Shin, R. H. Berg, and D. P. Schachtman, "Reactive oxygen species and root hairs in Arabidopsis root response to nitrogen, phosphorus and potassium deficiency," Plant and Cell Physiology, vol. 46, no. 8, pp. 1350-1357, 2005.

[12] R. Liso, G. Calabrese, M. B. Bitonti, and O. Arrigoni, "Relationship between ascorbic acid and cell division," Experimental Cell Research, vol. 150, no. 2, pp. 314-320, 1984.

[13] N. M. Kerk and L. J. Feldman, "A biochemical model for the initiation and maintenance of the quiescent center: implications for organization of root meristems," Development, vol. 121, no. 9, pp. 2825-2833, 1995.

[14] G. Potters, N. Horemans, R. J. Caubergs, and H. Asard, "Ascorbate and dehydroascorbate influence cell cycle progression in a tobacco cell suspension," Plant Physiology, vol. 124, no. 1, pp. 17-20, 2000.

[15] R. Liso, A. M. Innocenti, M. B. Bitonti, and O. Arrigoni, "Ascorbic acid induced progression of quiescent centre cells from G1 to S phase," New Phytologist, vol. 110, no. 4, pp. 469471, 1988.

[16] L. S. Lin and J. E. Varner, "Expression of ascorbic acid oxidase in zucchini squash (Cucurbita pepo L.)," Plant Physiology, vol. 96, no. 1, pp. 159-165, 1991.

[17] M. A. Green and S. C. Fry, "Apoplastic degradation of ascorbate: novel enzymes and metabolites permeating the plant cell wall," Plant Biosystems, vol. 139, no. 1, pp. 2-7, 2005.

[18] P. L. Conklin, S. A. Saracco, S. R. Norris, and R. L. Last, "Identification of ascorbic acid-deficient Arabidopsis thaliana mutants," Genetics, vol. 154, no. 2, pp. 847-856, 2000.

[19] T. Murashige and F. Skoog, "A revised medium for rapid growth and bioassays with tobacco tissue culture," Physiologia Plantarum, vol. 15, no. 3, pp. 437-497, 1962.

[20] K. Kampfenkel, M. Van Montagu, and D. Inzé, "Extraction and determination of ascorbate and dehydroascorbate from plant tissue," Analytical Biochemistry, vol. 225, no. 1, pp. 165167, 1995.

[21] P. Schopfer, C. Plachy, and G. Frahry, "Release of reactive oxygen intermediates (superoxide radicals, hydrogen peroxide, and hydroxyl radicals) and peroxidase in germinating radish seeds controlled by light, gibberellin, and abscisic acid," Plant Physiology, vol. 125, no. 4, pp. 1591-1602, 2001.

[22] X. Zhang, L. Zhang, F. Dong, J. Gao, D. W. Galbraith, and C. P. Song, "Hydrogen peroxide is involved in abscisic acid-induced stomatal closure in Vicia faba," Plant Physiology, vol. 126, no. 4, pp. 1438-1448, 2001.

[23] J. Foreman, V. Demidchik, J. H. F. Bothwell et al., "Reactive oxygen species produced by NADPH oxidase regulate plant cell growth," Nature, vol. 422, no. 6930, pp. 442-446, 2003.

[24] E. Olmos, G. Kiddle, T. K. Pellny, S. Kumar, and C. H. Foyer, "Modulation of plant morphology, root architecture, and cell structure by low vitamin C in Arabidopsis thaliana," Journal of Experimental Botany, vol. 57, no. 8, pp. 1645-1655, 2006.

[25] J. Tyburski, K. Dunajska, and A. Tretyn, "Reactive oxygen species localization in roots of Arabidopsis thaliana seedlings grown under phosphate deficiency," Plant Growth Regulation, vol. 59, no. 1, pp. 27-36, 2009. 
[26] F. Lai, J. Thacker, Y. Li, and P. Doerner, "Cell division activity determines the magnitude of phosphate starvation responses in Arabidopsis," Plant Journal, vol. 50, no. 3, pp. 545-556, 2007.

[27] G. Potters, L. De Gara, H. Asard, and N. Horemans, "Ascorbate and glutathione: guardians of the cell cycle, partners in crime?" Plant Physiology and Biochemistry, vol. 40, no. 6-8, pp. 537-548, 2002.

[28] K. Jiang, Y. L. Meng, and L. J. Feldman, "Quiescent center formation in maize roots is associated with an auxin-regulated oxidizing environment," Development, vol. 130, no. 7, pp. 1429-1438, 2003.

[29] J. T. Ward, B. Lahner, E. Yakubova, D. E. Salt, and K. G. Raghothama, "The effect of iron on the primary root elongation of Arabidopsis during phosphate deficiency," Plant Physiology, vol. 147, no. 3, pp. 1181-1191, 2008.

[30] L. Zheng, F. Huang, R. Narsai et al., "Physiological and transcriptome analysis of iron and phosphorus interaction in rice seedlings," Plant Physiology, vol. 151, no. 1, pp. 262-274, 2009.

[31] S. Abel, "Phosphate sensing in root development," Current Opinion in Plant Biology, vol. 14, no. 3, pp. 303-309, 2011.

[32] J. Jeong and M. L. Guerinot, "Homing in on iron homeostasis in plants," Trends in Plant Science, vol. 14, no. 5, pp. 280-285, 2009.

[33] J. Tyburski, K. Dunajska, and A. Tretyn, "A role for redox factors in shaping root architecture under phosphorus deficiency," Plant Signaling and Behavior, vol. 5, no. 1, pp. 64-66, 2010.

[34] T. R. Bates and J. P. Lynch, "Stimulation of root hair elongation in Arabidopsis thaliana by low phosphorus availability," Plant, Cell and Environment, vol. 19, no. 5, pp. 529-538, 1996. 

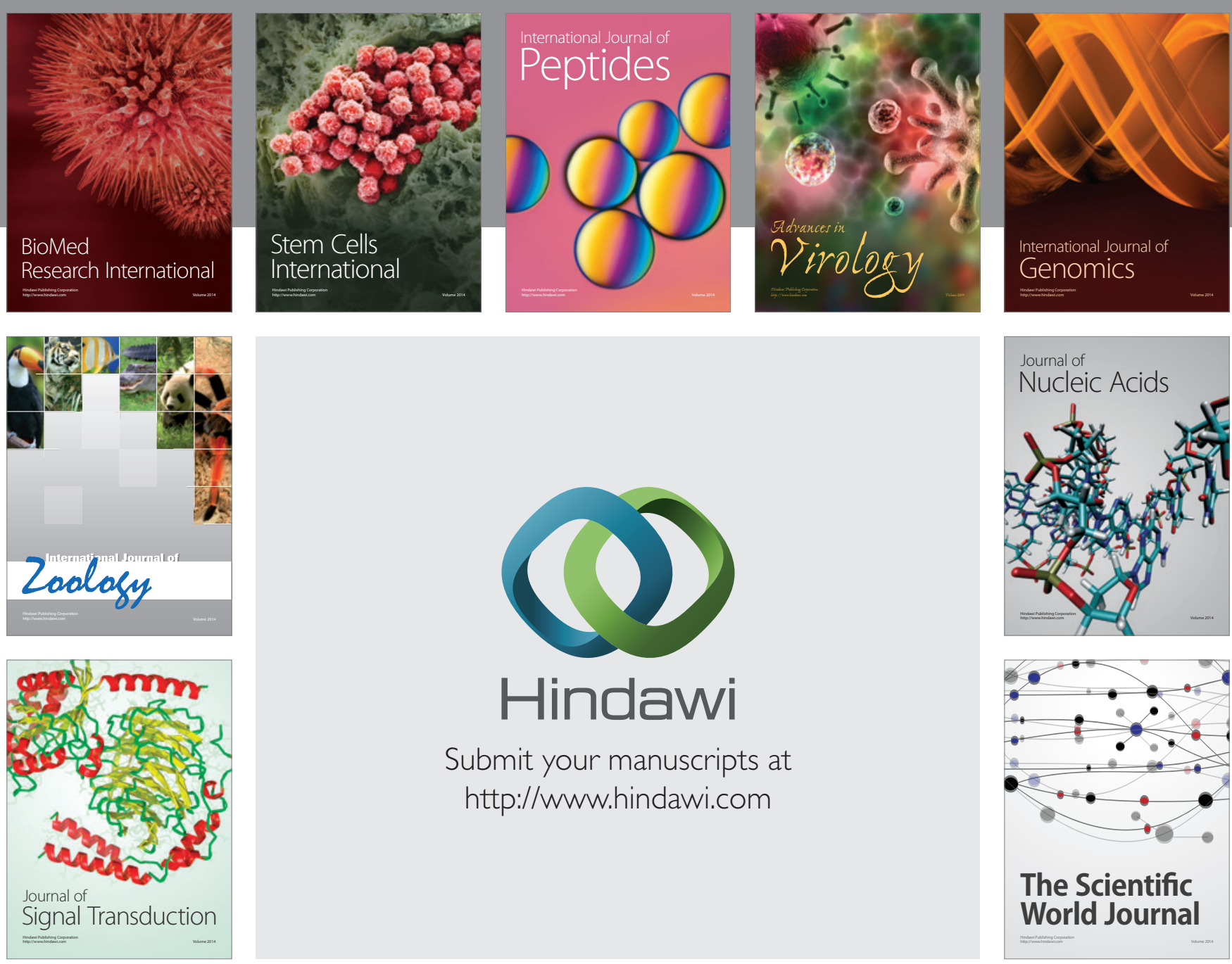

Submit your manuscripts at

http://www.hindawi.com
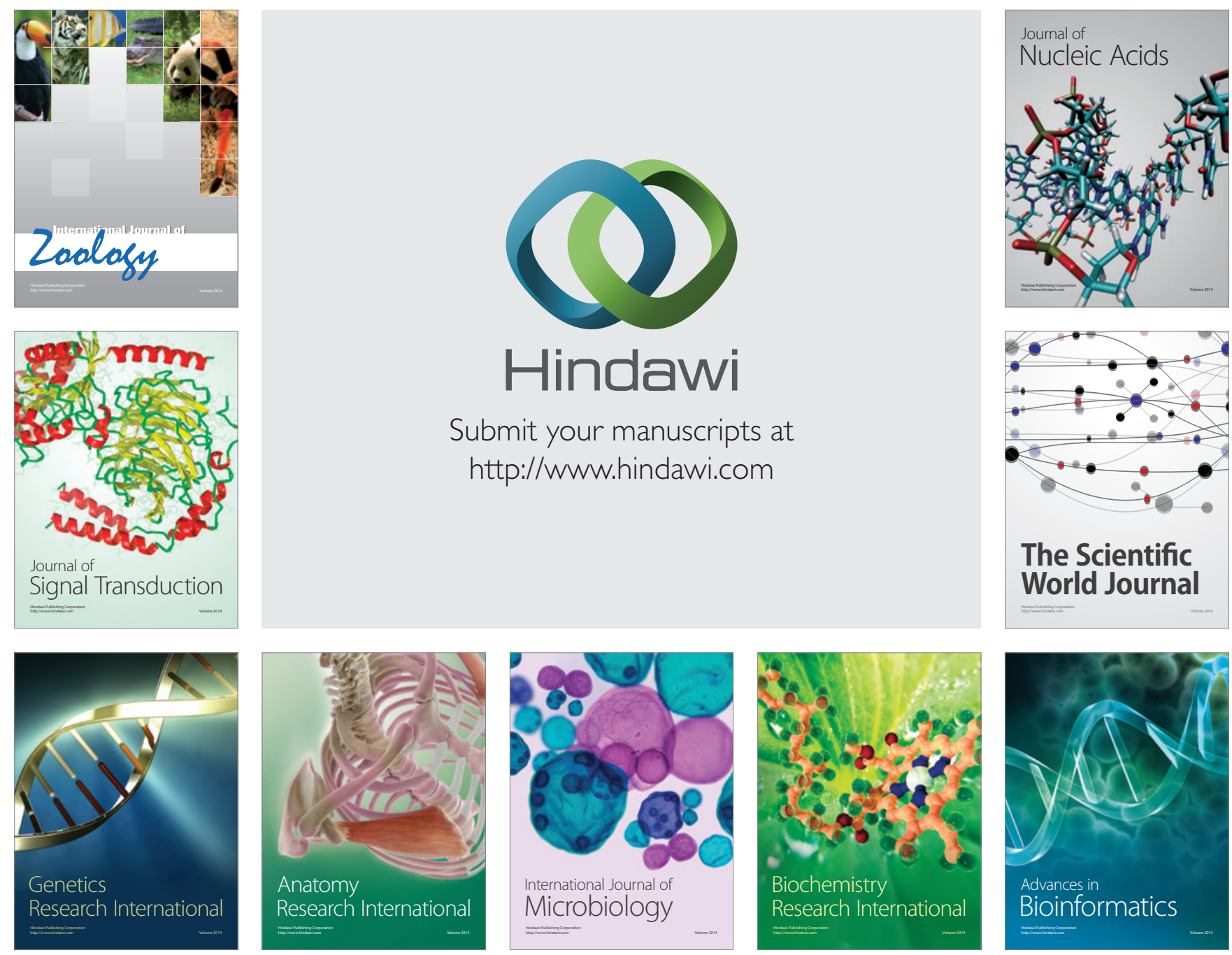

The Scientific World Journal
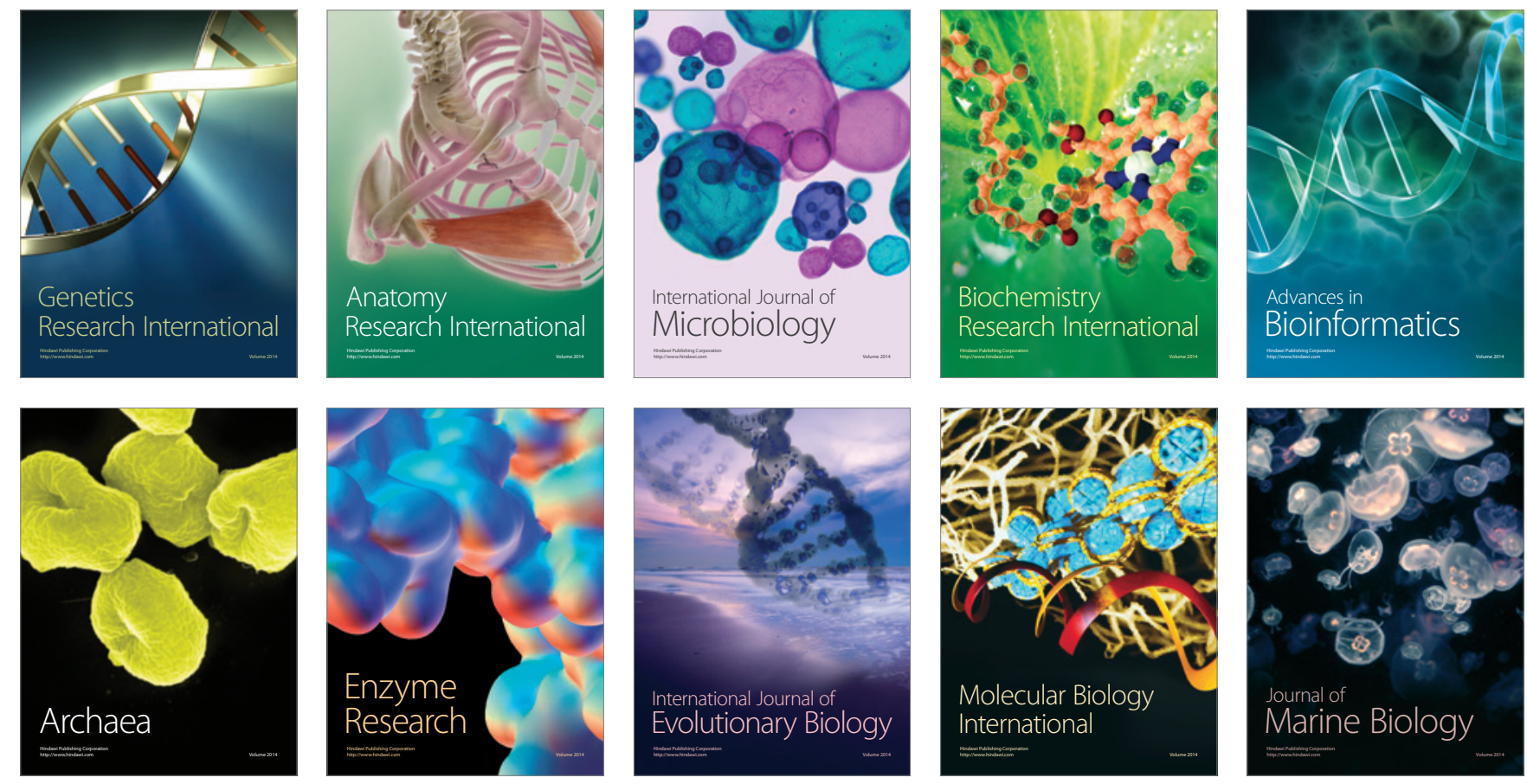